\title{
Examining Social Media Dimensions among a Cohort of Generation Y Consumers in South Africa
}

\author{
Nobukhosi Dlodlo \\ Lecturer, Department of Marketing and Sport Management \\ Faculty of Management Sciences, Vaal University of Technology \\ Email: nobukhosid@vut.ac.za \\ Professor Manillal Dhurup \\ Executive Dean, Faculty of Management Sciences \\ Vaal University of Technology \\ Email: manillald@vut.ac.za.
}

Doi:10.5901/mjss.2013.v4n14p329

\begin{abstract}
South Africa represents a microcosm of major global trends in social media among developing countries and this study presents various multi-dimensional constructs directed towards the intention to use social media tools among consumers. The purpose of this study is to explore the factors that affect the use of social media tools such as social networking sites, virtual worlds, microblogs and other Web 2.0 sharing applications. A quantitative study was followed using a structured questionnaire that incorporated existing scales. From the survey, 376 responses were returned, usable. Initially descriptive statistics such as frequencies were established with a view to understand the composition of the sample after which it was established that $58 \%$ $(n=219)$ of the respondents were male while $42 \%(n=157)$ were female. Thereafter, inferential statistics were employed through a factor analytical study which was applied using Principal Components Analysis with Varimax rotation. This analysis revealed four pertinent dimensions of social media usage. The reliability of the measuring instrument was assessed through Cronbach's coefficient alpha and revealed high internal consistency among the four identified constructs, namely; enjoyment (0.855), usefulness (0.802), ease of use (0.847) and critical mass (0.810). The identified dimensions have important implications to marketing practitioners in terms of social media spending allocation and extension of the marketing communication strategy; with social media as a pivotal element. However, future studies that integrate more robust statistical applications such as structural equation modelling (SEM) may be useful in validating the efficacy of the factors that were identified in this study.
\end{abstract}

Keywords: Social media, usefulness, enjoyment, ease of use, critical mass

\section{Introduction}

While "today's marketing managers are confronted with challenges that are analogous to reconfiguring an airplane while it is still in flight" (Trainor, Rapp, Beitelspacher \& Schillewaert, 2010:11), they also need to continuously cultivate and refigure marketing resources to form new capabilities that provide a sustainable strategic positioning. Businesses are challenged to develop and implement social media marketing strategies that incorporate enjoyment, ease of use and social exchange. More succinctly, Goldstuck (2012) has clearly demarcated social media as 'the quiet engine' of South African businesses. This notion therefore implies that, social media will go a long way in enabling the businesses to keep abreast of advances in marketing technology and further deliver product/service offerings on platforms that are acceptable to the masses.

The use of social media is growing at an astronomical rate among the emerging economies, among which South Africa is a part. Consumers are accessing social media on their desktops, laptops, notebooks, tablets and mobile devices. However, Masote (2012) predicted that by 2013, mobile devices would have overtaken desktop personal computers in terms of social media and web access. The South African Social Media Landscape study (2012) asserts that this projection has been fulfilled in South Africa whereby approximately $69 \%$ of the social media web traffic is accessed through mobile devices. This suggests that the upsurge in mobile social media market growth and access among developing countries has enjoyed numerous returns. Relatedly, these benefits include inter alia; increased return 
on investment (Hossain \& De Silva, 2009), expanded Gross Domestic Product (GDP) (Goldstuck, 2012), greater competitive advantage of businesses (Nair, 2011) and increased networking opportunities (Nordling, 2011).

Social media tools in South Africa have crossed the age barrier as well as the rural/urban divide with networking tools such as Facebook already going mainstream but still promising to be pervasive (Bosch, 2009). The technology plays the roles of communication, information and entertainment among South African users. For marketers, social media is important because notwithstanding its role as an enabler of business to consumer communication (Masote, 2012); the platforms are also an effective podium for consumer to consumer engagement (Mangold \& Faulds, 2009). Social media is unstructured and is focused on generating conversation and building community and may also have an influence on purchase decisions (Nair, 2011). Social media has provided a platform for consumers to conduct their information searches in their daily lives including their purchase decisions (Vollmer \& Precourt, 2008). Colliander \& Dahlen (2011) compared consumer reactions to blogs and online magazines and found that consumers exposed to information on blogs social networking sites had stronger brand attitudes and higher purchase intentions.

The South African Social Media Landscape study (2012) reveals that $95 \%$ of major brands surveyed have some form of social media strategy aimed at consumers. However, only $51 \%$ rate their efforts on Facebook as effective whilst only 33\% believe they are effective on Twitter (Goldstuck, 2012). The survey further highlights that corporate South Africa has woken up to social media, but it hasn't yet figured out how to dress for the role. This is because many local brands have been conducting their social media on an ad-hoc basis without having a comprehensive strategy in place. The current study aims to unravel the factor analytical structure that that presents the antecedents of social media among South African consumers. This is because the most important tool that South African firms can have at their disposal is the ability to adapt to changing technologies instead of remaining social media-phobic.

The current study focuses on the individuals who were born between 1987 and 1994. Those aged between 19 and 26 years represent the student population currently in tertiary institutions (Gangadharbatla, 2008; Bonds-Raacke \& Raacke, 2010) and are therefore regarded as representing the largest demographic group that are active on social media sites (Subrahmanyam et al., 2008). These individuals, referred to as millennial generation or Generation Y, are technology savvy and remain in the vanguard of those for whom web 2.0 technologies were created. This group of individuals is usually armed with BlackBerrys, Iphones, Ipads, laptops, notebooks, tablets and other technologies connected to the Internet mainframe, 24 hours a day, 7 days a week. These tools and gadgetry enable the individuals to organise their lives at school or university; beyond the reach of parents (away from home). However, the extant of the dimensions leading to their increased activity and purchase behaviour using social media tools is currently unknown and therefore this parameter merited the authors' attention in the current study.

\section{Theoretical Background}

The Technology Acceptance Model (TAM) that was developed by Davis, Bagozzi and Warshaw (1989) is the most used theory in adoption research (Venkatesh \& Bala, 2008). It postulates that the adoption of utilitarian information technologies is primarily determined by their perceived usefulness and perceived ease of use. Similarly, Subrahmanyam et al.(2008) as well as Bonds-Raacke and Raacke (2010) identify a broad range of functionalities and utilitarian features providing users with external benefits, such as the ability to organise events, setting reminders for friends' birthdays, or locating old friends. Relatedly, social media tools allow users to articulate a list of other users with whom they share a connection or similar interests (Boyd \& Ellison, 2007). Typical social media tools such as social networking sites allow a user to build and maintain a network of friends for social, professional or business interaction. This network could include brand communities or other users with similar purchase preferences.

Additionally, it has been shown that the adoption of hedonic information technologies that aim to provide selffulfilling value to the user; is a function of the degree to which the user experiences fun and pleasure when using the system (Van der Heijden, 2004). As suggested by the findings of Sledgianowski and Kulviwat (2008) as well as Hu, Poston and Kettinger (2011) and discussed multiple times by, for example; Boyd and Ellison (2007) as well as Thambusamy et al. (2010), consumers have a considerable degree of fun while using a plethora of social media tools such as social networking sites. Therefore, the level with which users experience joy from the social interactions that are enabled by various social media tools is presented as a critical underlying determinant of social media acceptance. Literature therefore supports that enjoyment is an additional social media influence factor (Sledgianowski \& Kulviwat, 2008; Hu et al., 2011; Venkatesh, Thong \& Xu, 2012). Therefore, building on a dual TAM background and by using an appropriate operationalisation of usefulness, we are able to address the inconsistent findings in the literature and are able to unravel the underlying constructs that explain the acceptance of social media among South African consumers. 
Combining these findings implies that social media tools are dual information technologies that are partly hedonic and partly utilitarian.

\section{Problem Investigated}

Social media is a largely unexplored area and currently just a 'buzzword' for both companies and academics within South Africa. Numerous publications on social media antecedents in developing countries exist; though a majority of these studies are either, preliminary benchmarks, theoretical reviews or market studies which do not provide deeper insight into technology acceptance issues. Notwithstanding the significance of this trajectory for marketers, limited attention has been devoted to usage of social media tools by consumers within the context of South Africa. Furthermore, researchers may be skeptical about the significance of social media technologies within the consumer market of developing countries. Unmistakably so, social media acceptance has proliferated amongst individual consumers (Eley \& Tilley, 2009).

One of the primary theoretical foundations of this study is the Technology Acceptance Model (TAM), which is widely used to explain the adoption of a new technology and information system. The theory is parsimonious and applicable in a variety of contexts, but, on the flip side, it is not sufficient to provide a richer understanding of the adoption of a social-based technology system (Claus-Peter, Pfeiffer \& Rothlauf, 2013). The present study aims to establish the efficacy of the two underlying constructs in TAM; namely; usefulness and ease of use within the context of social media platforms such as social networking sites, virtual worlds, microblogs and sharing surfaces. In addition, other multiple dimensions are identified and evaluated using exploratory factor analysis with a view to ascertain the holistic experiences of consumers and further provide the foundation for possible future comprehensive frameworks that predict the usage of social media tools within a South African context.

\section{Purpose of the Study}

This paper seeks to validate the findings advocated in previous studies on social media acceptance by extending the constructs developed in Davis (1989) technology acceptance model (TAM) among South African consumers. It employs a factor analytical approach to identify the determinants of social media acceptance as this has important implications to marketing practitioners in terms of social media spending allocation and extension of the marketing communication strategy; with social media as a requisite element. Additional descriptive measures, reliability and validity assessments are further conducted with a view to consolidate the efficacy of the identified constructs.

\section{Methodology}

To obtain an impartial perspective, a theoretical foundation was established through a literature review on social media antecedents among consumers. In addition, an empirical investigation using a quantitative research approach was further conducted with a view to collect primary data from the respondents using an adapted survey questionnaire. The rationale for selecting a quantitative study was that it is cheaper, flexible and allows for replication of the research procedure thus enhancing validity and reliability of research findings (Malhotra, 2010). Therefore, quantitative research surveys possess the objectivity and coherence that is necessary for identifying the fundamental idiosyncrasies' that underpin the acceptance of unique web 2.0 tools such as social media in South Africa.

\subsection{Population and the sample}

A non-probability purposive sampling method was used in the study to randomly select qualifying respondents. Churchill and lacobucci (2002) posit that in a purposive sample, the sample elements are selected because it is expected that they can serve the research purpose by contributing to the research questions. A sample size of 500 was chosen for the study; consistent with that used by a number of scholars in similar studies (Hsu \& Lin, 2008; Li, Chau \& Lou, 2005; Shih, 2004).

\subsection{Item generation and measuring instrument}

Three stages were used in the generation of the variables and factors to be included in the current study in the compilation of the scale. Firstly, a theoretical analysis was undertaken of previous studies on social media acceptance 
among consumers within different contexts with a view to establish consistently supported factors that influence social media uptake. Operational measures that were used in the measuring instrument were positioned on a Likert scale that was anchored at 1 (strongly disagree) to 7 (strongly agree). The items were slightly modified in order to make them more applicable within the context of social media. The Likert scale was used as it is relatively easy to construct, makes data easy to collect and analyse, thereby making them suitable for surveys (Kothari, 2008). Second, the authors examined other factors which would be appropriate to be included within the context of the study. The instrument that was used in the current study was adapted from the technology acceptance instruments of Hsu and Lin (2008); Shih (2004) and Davis (1989). However, some additional items were identified and included in the study because of strong support from literature and also because of their relevance. For example issues relating to the 'fun' and 'enjoyable' side of using social media applications were addressed as proposed by Venkatesh, Speier and Morris (2002). Similarly, the importance of a critical mass to support social media acceptance was not ignored in this study as elucidated by other proponent of the critical mass theory (Lou, Luo \& Strong, 2000; Hsu \& Lu, 2004). In addition, a demographic section was presented measuring different personal attributes of the respondents such as age, gender, race, income levels and education levels. The demographic questions were structured on dichotomous, multiple choice, interval and range responseformats.

\subsection{Data collection}

In order to increase representativeness and randomize the data collection procedure, data were collected over a period of 8 weeks at different times and days of the week. The consumer sample was regarded homogeneous in terms of demographic features such as age, race and types of applications utilised on social media platforms. A pilot-test of 50 respondents was conducted to investigate the initial reliability values of the scale. Several items were dropped due to low item-to-total correlations. At this point in the pilot-test, the goal was to retain a rich and diverse set of items. Where necessary some of the items were re-worded or re-phrased in line with the recommendations of two experts in the field of after a de-briefing exercise with two experts in the digital marketing and social media fields.

Informed consent was adhered to by utilising an accompanying letter and opening statements on the questionnaire, citing the purpose, nature and legitimacy of the study (Welman, Kruger \& Mitchell, 2005). Voluntary participation was encouraged and the respondents were informed that they were able to withdraw from the study, if they wished to do so. Confidentiality and anonymity was guaranteed through non-disclosure of the participants' real names. Of the 500 questionnaires that were distributed in the main survey, only 376 were returned and considered usable for the current study, giving a response rate of $75 \%$ for the study.

\subsection{Reliability and Validity of the study}

The reliability assessment for the social media instrument was ascertained by computing the cronbach alpha coefficient values as shown on Table 1. According to Nunally (1978), cronbach's alpha coefficients of less than 0.50 are deemed unacceptable; those between 0.50 and 0.69 are considered as being adequate whereas those above 0.70 are regarded as being acceptable. The sub-scale reliability values ranged between 0.802 and 0.855 while the standardized cronbach's alpha value for the entire scale was established at 0.879 indicating a satisfactory indication of internal reliability. Therefore, these results corroborate the sufficiency of the scale as being adequate in capturing the elements included as the social media acceptance determinants amongst South African consumers.

Table 1: Cronbach Alpha values for the social media acceptance dimensions

\begin{tabular}{lccc}
\hline \multicolumn{1}{c}{ Dimension/Construct } & $\mathrm{N}$ & Number of Items & Cronbach Alpha \\
\hline Enjoyment & 376 & 6 & .855 \\
Critical mass & 376 & 4 & .810 \\
Ease of use & 376 & 5 & .847 \\
Usefulness & 376 & 3 & .802 \\
\hline Overall Cronbach Alpha for the entire Scale $=\mathbf{0 . 8 7 9}$ & \\
\hline
\end{tabular}

Furthermore, the reliability of the scale as measured by coefficient alpha reflects the degree of cohesiveness among the scale items is an indirect indicator of convergent validity (Nunally \& Bernstein, 1994). Since the alpha values for the scale 
are greater than 0.70 in the current study, they can be regarded as reference for high convergent validity. In order to ascertain content validity, the questionnaire was pilot-tested with a sample of 50 conveniently selected respondents. Exploratory factor analysis (EFA) was conducted with a view to establish construct validity of the scale. Items that revealed no cross-loadings among the constructs and further indicated that an operation is similar to (converges on) other operations that it theoretically should also be similar to on the factor loadings; were identified. The results of the EFA study led to the establishment of a four-factor structure as shown on table 2 of this study.

\section{Data Analysis}

In the present study, data analysis was conducted using the Statistical Sciences for the Social Sciences (Version 20.0).

\subsection{Characteristics of the surveyed respondents'}

Table 2 shows the demographic characteristics of the respondents. The results indicate that there were 219 (approximately 58\%) male respondents and 157 (approximately 42\%) female respondents. The largest group of respondents (51\%) of the respondents was in the 21-23 years age-group while a majority of the respondents comprised respondents of African origin (325 respondents; $86 \%$ of the sample) owing to the location of the survey site; Gauteng province which predominantly constitutes of the black majority population in South Africa. With regard to the consumers' social media access points, approximately $66 \%$ of the sample (249 respondents) alluded to using their mobile devices with some alluding to using their office facilities (68 respondents; $18 \%$ of the sample); home Internet services (36 respondents; $10 \%$ of the sample) as well as public Internet domains (23 respondents; $6 \%$ of the sample). Prime usage social media tools was daily access (240 respondents; $64 \%$ of the sample) with a majority of the respondents (150 respondents; $40 \%$ of the sample) spending more than four hours per day while accessing online social media applications.

Table 2: Demographic profile of the respondents

\begin{tabular}{|c|c|c|c|c|}
\hline Variable & Categories & $\begin{array}{l}\text { Population } \\
(\mathrm{N})\end{array}$ & $\begin{array}{l}\text { Sample Frequency } \\
\text { (n) }\end{array}$ & $\begin{array}{c}\text { Percentage } \\
(\%)\end{array}$ \\
\hline \multirow{2}{*}{ Gender } & Males & 376 & 219 & 58 \\
\hline & Females & 376 & 157 & 42 \\
\hline \multirow{3}{*}{ Age } & Between $18-20$ years & 376 & 118 & 31 \\
\hline & Between 21-23 years & 376 & 191 & 51 \\
\hline & Between $24-26$ years & 376 & 67 & 18 \\
\hline \multirow{4}{*}{ Race/Ethnicity } & African/Black & 376 & 325 & 86 \\
\hline & White & 376 & 19 & 5 \\
\hline & Indian & 376 & 7 & 2 \\
\hline & Coloured & 376 & 25 & 7 \\
\hline \multirow{4}{*}{$\begin{array}{l}\text { Social media access } \\
\text { point }\end{array}$} & Mobile phone & 376 & 249 & 66 \\
\hline & Office or university & 376 & 68 & 18 \\
\hline & Internet café & 376 & 23 & 6 \\
\hline & Home Internet & 376 & 36 & 10 \\
\hline \multirow{5}{*}{$\begin{array}{l}\text { Frequency of social } \\
\text { media usage }\end{array}$} & Less than 3 times per month & 376 & 13 & 3 \\
\hline & Between 3-6 times per month & 376 & 10 & 2 \\
\hline & Once a week & 376 & 36 & 10 \\
\hline & Between 2-4 times a week & 376 & 77 & 21 \\
\hline & Daily & 376 & 240 & 64 \\
\hline \multirow{4}{*}{$\begin{array}{l}\text { Daily amount of time } \\
\text { spent on social media } \\
\text { platforms }\end{array}$} & Less than one hour & 376 & 76 & 20 \\
\hline & Between $1-2$ hours & 376 & 91 & 24 \\
\hline & Between 3-4 hours & 376 & 59 & 16 \\
\hline & More than 4 hours & 376 & 150 & 40 \\
\hline
\end{tabular}

\subsection{Exploratory Factor Analysis and psychometric properties of the scale}

A common factor route with Varimax rotation was used to extract factors. Prior to factor extraction the Bartlett's test of 
Sphericity and the Kaiser- Meyer-Olkin (KMO) measure of sampling adequacy was conducted to establish whether the factor analysis procedure was appropriate for the data set. The Bartlett's test of Sphericity was significant at $p<0.000$ inferring that the data set was not an identity matrix with zero correlations. In addition, the test revealed a chi square value $\left(X^{2}\right)$ of 3753.686 and a KMO measure of sampling adequacy at a value of $0.748(>0.50)$, further confirming appropriateness of the data set for factor analysis.

Table 3: Rotated factor loading matrix and psychometric evaluation of the scale

\begin{tabular}{|l|c|c|c|c|}
\hline \multirow{2}{*}{ Item } & \multicolumn{3}{c|}{ Component/Factor } \\
\cline { 2 - 5 } & 1 & 2 & 3 & 4 \\
\hline Social media gives me pleasure & .588 & -.199 & -.017 & .416 \\
\hline Social media is fun & .838 & -.042 & -.100 & .082 \\
\hline Social media is appealing & .595 & -.166 & .014 & .414 \\
\hline Social media is exciting & .846 & -.078 & .179 & .116 \\
\hline Social media is enjoyable & .803 & .209 & -.045 & .146 \\
\hline Social media is entertaining & .784 & .161 & .037 & .044 \\
\hline Social media acceptance depends on what my colleagues think & .211 & .009 & .003 & .606 \\
\hline Acceptance depends on people who are important to me & .088 & -.092 & .229 & .681 \\
\hline Acceptance depends on my friends & .039 & -.020 & -.004 & .824 \\
\hline Acceptance depends on majority usage by community & .217 & .020 & -.100 & .736 \\
\hline Social media acceptance improves my work performance & -.056 & .254 & .842 & -.005 \\
\hline Social media acceptance improves my work effectiveness & .051 & .107 & .920 & .038 \\
\hline Social media acceptance improves my work productivity & .044 & .194 & .851 & .089 \\
\hline Social media tools are simple to use & .293 & .666 & .113 & .099 \\
\hline Social media tools are understandable & -.135 & .766 & .307 & -.294 \\
\hline Social media tools are flexible & .059 & .711 & .365 & -.231 \\
\hline Overall, I believe social media tools are easy to use & -.008 & .853 & .219 & -.139 \\
\hline Participation would not require a lot of mental effort & -.135 & .682 & -.082 & .242 \\
\hline Explained variance & 20.074 & 16.654 & 14.900 & 14.868 \\
\hline Cumulative \% of variance & 20.074 & 26.728 & 51.628 & 66.495 \\
\hline Eigen Values & 4.503 & 4.009 & 1.917 & 1.539 \\
\hline
\end{tabular}

*Loadings of 0.50 and more were considered significant. Extraction method: Principal Component Analysis. Varimax rotation with Kaiser Normalization.

The percentage of variance explained, the scree plot and eigenvalue criterion guided the extraction of factors. The total variance explained by the extracted factors is $66.5 \%$ which according to Malhotra (2010) is satisfactory. Regarding the eigenvalues, the general rule is to retain all factors with eigenvalues greater than 1.0 whose total variance contribution is considered significant (Zikmund, 2000). Item reduction and scale purification was undertaken whereby items with low factor loadings, communalities and low-item-to-total correlations were investigated. In addition, items that loaded heavily on more than one factor were eliminated from further scale development with a view to enhance "interpretability of the factor structure" (Malhotra, 2010:643). A minimum cut-off of 0.50 was used on the variable loadings. This is consistent with Hair et al. (2010) who suggest that factor loadings greater than \pm 0.30 are considered to meet the minimum levels, loadings of \pm 0.40 are considered important, and loading of \pm 0.50 and greater are considered more important. Resultantly, five items were eliminated because of cross loading as such cross-loading suggests that the item may be incapable of differentiating between factors. This procedure resulted in the extraction of four meaningful factors, which were labelled enjoyment, critical mass, usefulness and ease of use. Table 3 summarises the factor structure and psychometric evaluation of the scale.

\subsection{Descriptive statistics for the identified dimensions}

Table 4 presents the descriptive statistics of the study through the mean scores and standard deviation values. The purpose of compiling mean score rankings were to provide a rating on the social media acceptance attribute in terms of the level of importance from the perspective of the consumers. The minimum (1) and maximum (7) values are based on the lowest and highest values on a seven-point Likert scale. The means were calculated by summating the response values of variables that comprised each dimension divided by the number of variables in each dimension. 
Table 4: Descriptive statistics of the social media acceptance dimensions

\begin{tabular}{lccc}
\hline Dimension/Construct & Mean Score Ranking & Mean factor scores $(\overline{\mathbf{x}})$ & Standard Deviation \\
\hline Enjoyment & 1 & 5.602 & 7.449 \\
Critical mass & 2 & 5.502 & 4.585 \\
Ease of use & 3 & 5.334 & 9.052 \\
Usefulness & 4 & 5.123 & 10.094 \\
\hline Minimum mean value= 1 and Maximum mean value=7 & &
\end{tabular}

The results indicate that all four dimensions presumed mean score ratings that were above 4 revealing that the respondents were more inclined to agreeing and strongly agreeing that the four identifiable sub-scales are key explanatory descriptors of social media usage. The enjoyment dimension was rated the most important $(\bar{x}=5.602$; $\mathrm{SD}=7.449)$ followed closely by critical mass $(\overline{\mathrm{x}}=5.502 ; \mathrm{SD}=4.585)$ and ease of use $(\overline{\mathrm{x}}=5.334 ; \mathrm{SD}=9.052)$. Nonetheless, the lowest mean rating among the dimensions turned out to be usefulness $(\bar{x}=5.123 ; S D=10.094)$. These findings reveal that on an average rating of 4 and above, all dimensions are moderately important in explaining social media technology acceptance amongst South African consumers. The results indicate that in order for marketing managers to maintain sustained patronage on all their social media platforms; all the aforementioned technology acceptance attributes need to be enhanced with a view to create a total social networking experience for consumers as opposed to focusing on a single dimension.

\section{Results and Discussion}

The primary objective of the study was to empirically test a social media acceptance scale. Factor one, labelled 'enjoyment' (Variance $=20.074 \%$; eigenvalue $=4.503$ ) comprised six variables that relate mainly to the affective elements derived from accepting social media tools. In addition, this factor was ranked highest on the mean score rankings $(\bar{x}=5.602 ; s . d=7.449)$ indicating the relative importance with which the respondents reflected on their ability to derive pleasure from interacting on various social media platforms. The scale items that loaded onto the factor relate mainly to the respondents adopting various social media platforms owing to the perceived level of pleasure, fun, appeal, excitement, entertainment and other positive experiences that are associated with the user interacting with the social media tools. These attributes are both inherent in the activity itself and are generated in the process of performing the activity (Davis, Bagozzi \& Warshaw, 1992; Venkatesh et al., 2012). Therefore, social media technology enjoyment is a form of intrinsic motivation which indicates that an individual conducts an activity for its own sake; such as fun, enjoyment and pleasure (Igbaria et al., 1996). These attributes are both inherent in the acceptance of various social media tools as well as in their usage per se (Venkatesh et al., 2002). In the context of using social media technology, the intrinsic motivation may be derived from the interactions with other communication partners or the enjoyment and pleasures conveyed from those partners on the social networking platforms.

Factor two was labelled 'ease of use' (Variance=16.654\%; eigenvalue =4.009) comprised five variables that relate to the user-friendliness associated with various social media tools as measured by the understandability, simplicity, effortless and flexible nature of conducting various purchasing activities on the platforms. In addition, this factor was ranked third on the mean score rankings $(\bar{x}=5.334 ; s . d=9.052)$ indicating the relative modesty with which the respondents reflected on their perceptions of the user-friendliness or effortless of various features existing on various social media platforms.A consumer's perceptions of the ease of use of social media technology reflects his/her individual assessment that the technology interaction process will be relatively free of cognitive burden (Agarwal \& Karahanna, 2000) or "the degree to which a person believes that using a particular system would be free of effort" (Davis, 1989:320). Therefore, it has been shown that consumers are more likely to interact with new technologies if they perceive that relatively little cognitive effort will be expended during the interaction process. According to Davis (1989), perceived ease of use represents an intrinsically motivating aspect of human-computer interactions. Past research found direct or indirect effect of the perceived user friendliness of a system on the adoption of Internet technology (Davis, et al., 1989; Hu, et al., 1999; Cheung, et al., 2003). The findings of a study conducted by Venkatesh (2000) reveal that ease of use is the underlining dimension that influences acceptance decisions of social media technologies among users. In most cases this factor is explained within the context of the technical aspects related to the technology such as straightforward connectivity, shorter loading times and easier navigation across the network pages.

Factor three was labelled 'usefulness' (Variance=14.900\%; eigenvalue $=1.917$ ) comprised three variables that 
relate to the utilitarian value derived from using social media tools such as work productivity, efficiency as well as performance. In addition, this factor was ranked lowest (fourth) on the mean score rankings ( $\bar{x}=5.123$; s.d $=10.094$ ) indicating that the respondents agreed that they were able to derive some utilitarian benefits (to a limited extent) through the acceptance and usage of social media platforms. The low mean score ranking was probably as a result of usefulness being a construct that was initially adapted by Davis (1989) for use in work environments and not for assessing the consumption behavioural patterns of consumers using social tools that are usually based on uswr-generated content. However, the factor analysis results confirm the validity of this factor the degree to which a consumer believes that using social media platforms will enhance his/her work, learning and purchase performance decisions and activities. This factor relates to the respondents' very general perception about the efficiency of social media technology in providing utility by supporting one's productivity and performance. In the current study, the utility of social media technology is a combination of both technological features and the attributes of the online social networking context in enhancing the work performance, learning effectiveness and general life productivity among South African consumers. Indeed, the findings concerning the influence of the usefulness dimension on Internet adoption behavior substantially differ from one another (Claus-Peter et al., 2013). We believe therefore, that the findings concerning the influence of usefulness on social media acceptance is largely heterogeneous because the measurements of perceived usefulness differ greatly across various studies and contexts.

Factor four was labelled 'critical mass' (Variance $=14.868 \%$; eigenvalue $=1.539$ ) comprised four variables that relate to the importance of community in social media platforms. In addition, this factor was ranked second on the mean score rankings $(\bar{x}=5.502 ; s . d=4.585)$ indicating that the respondents considered the social presence of an online community as being pertinent towards their decisions to interact on various social media platforms. Unlike traditional information technologies, social media requires collective efforts and interdependence between two or more people and this is fostered through conversation and sharing (Markus, 1987). Relatedly, the total number of registered members determines the sacrosanctity of a particular social media platform and adds value for its members and vendors alike (Gangadharbatla, 2008). Therefore, it may be posited that the benefits of using social media can therefore be derived in the presence of social presence and networking community (Alarcón-del-Amo et al., 2012; Claus-Peter et al., 2013). Relatedly, perceptions of critical mass are rapidly strengthened as more people participate in network activities. As noted earlier, an individual may demonstrate a positive attitude towards social media technology based on a subjective perception of the critical number of current users (Lou et al., 2000; Li et al., 2005).

\section{Strengths, Limitations and Directions for Future Research}

The strength of this study lies in its explorative use of a quantitative research approach. Findings of the study constitute an important source of knowledge and information on issues pertaining to the underlying dimensions impacting on social media acceptance within the context of South African consumers. However, the study has a limitation in that its results are restricted to one province in South Africa only. In order to refine the results, similar studies could be conducted in different provinces across South Africa. Furthermore, the limited sample size of 376 respondents has the potential to limit the generalisability of the research findings at national level and subsequent conclusions derived. Furthermore, the study did very little to specify which type of social media applications respondents were utilizing during their consumption activities. These limitations may indicate that caution is needed in the interpretation of these findings as these results may not be accepted as completely relevant in diverse settings. Also, it is important to note that while the four dimensions were identified and distinguished in this study as being the salient underlying dimensions towards consumer acceptance of social media applications, other dimensions may remain important in different environments and could still be explored in future studies.

In addition, frameworks can be developed using more robust statistical tools such as Structural Equation Modelling to test the statistical validity of the identified antecedents and further hypothetically test the relationships among the identified constructs with other extraneous variables. A due consideration of the diverse nature of the South African consumer market can foster new perspectives with which to establish research enquiry into the web 2.0 technology acceptance paradigm. For example, social media acceptance can also be investigated using various demographic variables such as gender, age group, ethnicity as well as education level of the consumers. This study should also be extended to other social media applications such as weblogs, wikis, vlogs and more specific social networking sites such as Google+, twitter and Facebook. There is a need to internationalise this scholarship in a manner that pinpoints similarities and differences between South African and non-African consumers regarding their attitudes and behavioural intentions towards the usage of social media by and large. Cross-country comparative studies may also be conducted to 
determine this phenomenon across different respondents in a plethora of cultures.

\section{Conclusions}

The explosion of social media as a catalyst of change among businesses in South Africa and beyond, presents implications that cannot be underestimated. Four dimensions underlying social media usage were established in the study, namely; enjoyment, ease of use, critical mass and usefulness. Whereas ease of use captures how easy the interaction with information technologies is; enjoyment, usefulness and critical mass capture the hedonic, utilitarian and social community cohesiveness aspects associated with social media technologies. These findings imply that social media usage by South African consumers is largely based on the hedonic, utilitarian, user-friendliness as well as availability of communities on the online systems. In a real-world setting, this research presented the opportunity to study the underlying variables that are fundamental towards the acceptance of social media as a relevant tool for purchasing activities by both novices as well as experienced users. The findings, therefore, help us better understand the assortment of social media antecedents that are an essential ingredient when developing an extended promotional strategy that is based on virtual platforms; particularly, social media. In technology acceptance and adoption research, this study provided valuable insight into the acceptance and usage of new web 2.0 based technologies amongst a consumer setting.

\section{References}

Agarwal, R. \& Karahanna, E. (2000). Time flies when you're having Fun: cognitive absorption and beliefs about Information Technology usage. MIS Quarterly, 24(4), 665-694.

Alarcón-Del-Amo, M. D. C., Lorenzo-Romero, C. \& Gómez-Borja, M. A. (2012). Analysis of acceptance of social networking sites. African Journal of Business Management, 6(29), 8609-8619.

Bonds-Raacke, J. \& Raacke, J. (2010). Myspace and facebook: Identifying dimensions of uses and gratifications for friend networking sites. Individual Differences Research, 8(1), 27-33.

Bosch, T. E. (2009). Using online social networking for teaching and learning: Facebook use at theUniversity of Cape Town. South African Journal for Communication Theory and Research, 35(2): 185-200.

Boyd, D. M. \& Ellison, N. B. (2007). Social network sites: Definition, history, and scholarship. Journal of Computer-Mediated Communication, 13(1), 210-230.

Cheung, C., Zhu, L., Kwong, T., Chan, G. \& Limayem, M. (2003). Online consumer behaviour: a review and agenda for future research, in: Proceedings of the 16th Bled eCommerce Conference, 194-218.

Churchill, G.A. (Jr) \& lacobucci, D. (2002). Marketing research: Methodological foundations. (8th ed). Fort Worth: Harcourt College Publishers.

Claus-Peter, H., Jella Pfeiffer, E. \& Rothlauf, F. 2013. Hedonic and Utilitarian Motivations of Social Network Site Adoption. Working paper, 13/1. Johannes Gutenberg-University Mainz: Germany.

Colliander, J. \& Dahlén, M. (2011). Following the fashionable friend: The power of social media weighing publicity effectiveness of blogs versus online magazines. Journal of Advertising Research, 51(1), 313-320.

Davis, F. D. (1989). Perceived Usefulness, Perceived Ease of Use, and User Acceptance of Information Technology. MIS Quarterly, (13), 319-340.

Davis, F. D., Bagozzi, R. P. \& Warshaw, P. R. (1989). User acceptance of computer technology: a comparison of two theoretical models. Management Science, 35(1), 982-1002.

Davis, F. D., Bagozzi, R. P. \& Warshaw, P. R. (1992). Extrinsic and Intrinsic Motivation to Use Computers in the Workplace. Journal of Applied Social Psychology, 22(14), 1111-1132.

Eley, B. \& Tilley, S. (2009). Online Marketing, Inside Out. Melbourne: Site Point.

Gangadharbatla, H. (2008). Facebook me: Collective self-esteem, need to belong, and internet self-efficacy as predictors of the igeneration's attitudes toward social networking sites. Journal of Interactive Advertising, 8(2), 5-15.

Goldstuck.A. (2012). The quiet engine of the South African Economy. Internet matter, pp.2. March. 2012.

Hair, J. F., Black, W. C., Babin, B. J. \& Anderson, R. E. (2009). Multivariate data analysis. (7th ed.). Prentice Hall, Upper Saddle River, NJ.

Hossain, L. \& de Silva, A. (2009). Exploring user acceptance of technology using social networks. Journal of High Technology Management Research, 20(1), 1-18.

Hsu, C. L. \& Lu, H. P. (2004). Why do people play on-line games? An extended TAM with social influences and flow experience. Journal of Information \& Management, 41(1), 853-868.

Hsu, C-L \& Lin, J-C. (2008). Acceptance of blog usage: The roles of technology acceptance, social influence and knowledge sharing motivation. Information \& Management, 45(1), 65-74.

$\mathrm{Hu}, \mathrm{P} ., \mathrm{Chau}, \mathrm{P}$., Sheng, O. \& Tam, K. (1999). Examining the technology acceptance model using physician acceptance of telemedicine 
technology. Journal of Management Information Systems, 16(2), 91-112.

Hu, T., Poston, R. S. \& Kettinger, W. J. (2011). Non-adopters of online social network services: Is it easy to have fun yet? Communications of the Association for Information Systems, 29(1), 441-458.

Igbaria, M., Parasuraman, S. \& Baroudi, J. (1996). A Motivational model of micro-computer usage. Journal of Management Information Systems, 13(1), 127-143.

Kothari, C. R. (2008). Research Methodology: Methods and Techniques. (2nd ed.). New Delhi: New Age International.

Li, D., Chau, P. Y. K. \& Lou, H. (2005). Understanding Individual Adoption of Instant Messaging: An Empirical Investigation. Journal of the Association for Information Systems, 6(4), 102-129.

Lou, H., Luo, W. \& Strong, D. (2000). Perceived Critical Mass Effect on Groupware Acceptance. European Journal of Information Systems, (9)2, 91-103.

Malhotra, N. K. (2010). Marketing research: an applied orientation. Eaglewood Cliffs, N.J: Prentice-Hall.

Mangold, W.G. \& D.J. Faulds (2009). Social media: The new hybrid element of the promotion mix. Business Horizons, 52(4), $357-365$.

Markus, M. L. (1987). Toward a Critical Mass Theory of Interactive Media: Universal Access, Interdependence and Diffusion. Communication Research, 14(5), 491-511.

Masote, M. (2012). Tablet users hungry for data. Sunday Times: Business Times, March 11, p. 7.

Nair, M. (2011). Understanding and measuring the value of social media. The Journal of Corporate Accounting and Finance, 22(3), 4551.

Nordling, L. 2011. Transforming science strategy in the developing world. Nature, [Online] Available: http://www.nature.com/news /2011/110218/full/news.2011.108.html (July 20, 2013).

Nunnally, J.C. 1978. Psychometric Theory. (2nd ed.). New York: McGraw Hill.

Nunnally, J. C \& Bernstein, I. H. (1994). Psychometric Theory. (3rd ed.). New York: McGraw-Hill.

Shih, H. P. (2004). Extended technology acceptance model of Internet utilisation behaviour, Information \& Management Journal, 41 (6), 719-729.

Sledgianowski, D. \& Kulviwat, S. (2008). Social network sites: Antecedents of user adoption and usage. Americas Conference on Information Systems 2008 Proceedings. Paper 83. Toronto: Canada.

Subrahmanyam, K., Reich, S. M., Waechter, M. \& Espinoza, G. (2008). Online and offline social networks: Use of social networking sites by emerging adults. Journal of Applied Developmental Psychology, 29(6), 420-433.

South African Social Media Landscape: Social Media breaks barriers in South Africa (2012). [Online] Available http://www.worldwideworx.com/wp-content/uploads/2012/10/Exec-Summary-Social-Media-2012 (February 29, 2013).

Thambusamy, R., Church, M., Nemati, H. \& Barrick, J. (2010). Socially exchanging privacy for pleasure: Hedonic use of computermediated social networks. ICIS 2010 Proceedings. Paper 253.

Trainor, K. J., Rapp, A., Beitelspacher, L.S. \& Schillewaert, N. (2010). Integrating information technology and marketing: An examination of the drivers and outcomes of e-marketing capability. Industrial Marketing Management, doi:10.1016/j.indmarman.2010.05.001.

Van Der Heijden, H. (2004). User acceptance of hedonic information systems. MIS Quarterly, 28(4), 695-704.

Venkatesh, V. (2000). Determinants of perceived ease of use: Integrating perceived behavioral control, computer anxiety and enjoyment into the technology acceptance model. Information Systems Research, 11(4), 342-365.

Venkatesh, V. \& Bala, H. (2008). Technology acceptance model 3 and a research agenda on interventions. Decision Sciences, 39(2), 273-315.

Venkatesh, V., Speier, C. \& Morris, M. G. (2002). User Acceptance enablers in individual decision making about technology: toward an integrated model, Decision Sciences, 33 (2), 297-315.

Venkatesh, V., Thong, J. Y. L. \& Xu, X. (2012). Consumer acceptance and use of information technology: Extending the unified theory of acceptance and use of technology. MIS Quarterly, 36(1), 157-178.

Vollmer, C., \& Precourt, G. (2008). Always on: Advertising, marketing and media in an era of consumer control. New York: McGraw-Hill.

Welman, J. C., Kruger, S. J. \& Mitchell, B. C. (2005). Research Methodology (3rd ed.). Cape Town: Oxford University Press Southern Africa. 